\title{
Public health cuts will affect oral health, warns BDA
}

\author{
By Adrian O’Dowd
}

Dentists' leaders have criticised the government for $£ 85$ million worth of cuts to public health grants, saying they will unfairly affect oral health services.

On 20 December 2018, the Department of Health \& Social Care published guidance ${ }^{1}$ on public health grants to local authorities for 2019-20 in which it confirmed the grant of $£ 3.13$ billion was being reduced by $3.3 \%$ on the previous year's fund of $£ 3.22$ billion for spending on the likes of smoking cessation, obesity services and sexual health clinics.

Jon Ashworth MP, Labour's Shadow Health and Social Care Secretary, said: 'It's outrageous the Government have tried to sneak out further devastating cuts without debate in Parliament. Only a few weeks ago the Secretary of State told us prevention was his priority and yet today he is cutting specialist public health services by a further $£ 85$ million. It's the clearest evidence that ministerial promise on the NHS are entirely hollow.'

Local authorities in England are responsible for public health, but the BDA believes councils have been denied resources to make an effective stand against preventable conditions like tooth decay and obesity.

The union said that 130 out of 152 local authorities (85\%) reduced their public health budgets in 2018-19 and cited studies by health think tank The Kings Fund that found the single biggest areas for cuts have been miscellaneous services, including dental public health.

Tooth decay is the main reason for hospital admissions among young children, with paediatric tooth extractions costing the NHS $£ 205$ million since 2012, said the BDA, and effective long-term investment in early years oral health programmes in nurseries and primary schools in Scotland had saved millions on treatment costs.

BDA Chair Mick Armstrong said: 'Matt Hancock says he wants prevention to be the focus of a 21st century NHS. Public health should be the foundation for that approach, but in place of investment Westminster has simply devolved savage cuts.

'It's utterly perverse that wholly preventable conditions are now going effectively unchecked. Starving local authorities of needed resources is hopelessly short-sighted, and is only piling pressure on NHS services.'

The warning came as Public Health England (PHE) launched a Change4Life significantly reducing their sugar intake.' Meanwhile, England's Chief Medical Officer (CMO), Dame Sally Davies, recently added her support to the call for the sugar levy currently imposed on sugary soft drinks to also be added to milk-based drinks - an idea supported by the BDA.

In her annual report ${ }^{3}$ published on 21 December 2018, Dame Sally called on the

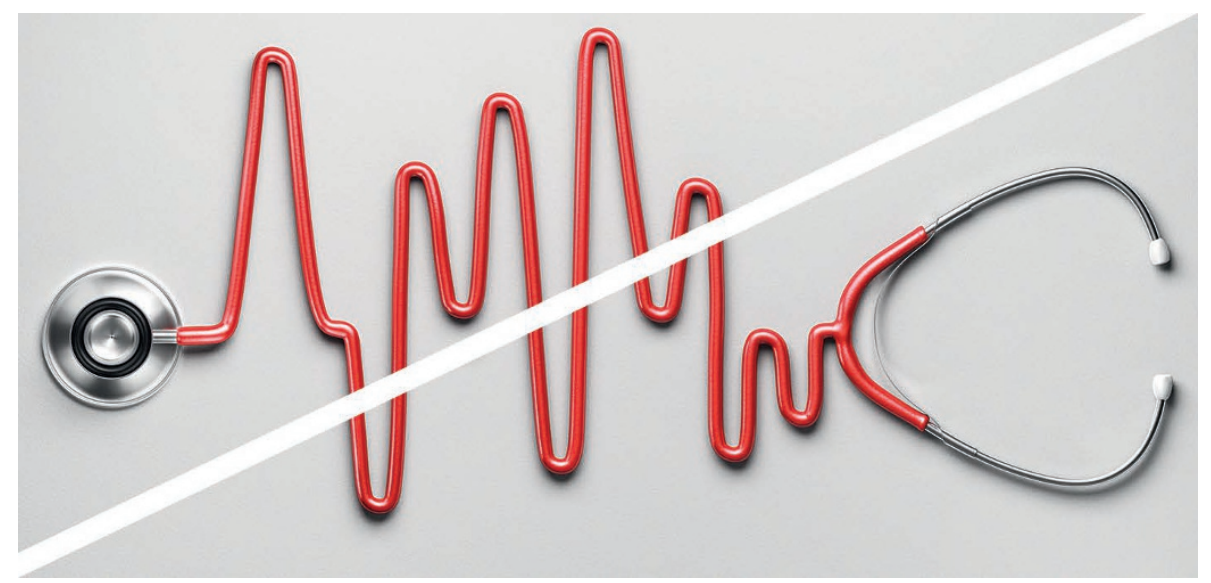

campaign ${ }^{2}$ on 2 January 2019 to support families to cut back on sugar and to help tackle growing rates of childhood obesity.

PHE said that although children's sugar intakes had declined slightly in recent years, they were still consuming around eight excess sugar cubes each day - equivalent to around 2,800 excess sugar cubes per year.

Children were already exceeding the maximum recommended sugar intake for an 18-year-old by the time they reach their tenth birthday, said PHE, based on their total sugar consumption from the age of two.

Dr Alison Tedstone, Chief Nutritionist at PHE, said: 'Children are consuming too much sugar, but parents can take action now to prevent this building up over the years.

'To make this easier for busy families, Change4Life is offering a straightforward solution - by making simple swaps each day, children can have healthier versions of everyday foods and drinks, while government to consider imposing taxes on foods high in sugar and salt, as it has done with sugary drinks, and accused the food industry of failing to help deliver healthier diets.

In her annual report, Dame Sally Davies said tougher action was needed. She wanted a ban on added sugar in baby milk and baby foods, and called for the sugar levy to include milk drinks that contain added sugar. Her report also recommends incentives to increase fruit and vegetable consumption, such as price subsidies.

1. Department of Health \& Social Care. Public Health Grants to Local Authorities: 2019 to 2020. 2018. Available at https://www.gov.uk/government/publications/ public-health-grants-to-local-authorities-2019-to-2020 (accessed January 2019).

2. Public Health England. Sugar Swaps for Kids Campaign - Change4Life. Available at https://www.nhs.uk/ change4life/food-facts/sugar/sugar-swaps-for-kids (accessed January 2019).

3. Department of Health \& Social Care. Annual Report of the Chief Medical Officer, 2018. 2018. Available at https://www.gov.uk/government/publications/ chief-medical-officer-annual-report-2018-better-health-within-reach (accessed January 2019). 